\title{
Curricula for teaching the content of clinical practice guidelines to family medicine and internal medicine residents in the US: a survey study
}

\author{
Elie A Akl ${ }^{* 1,2}$, Reem Mustafa ${ }^{1}$, Mark C Wilson ${ }^{3}$, Andrew Symons ${ }^{2}$, \\ Amir Moheet ${ }^{4,5}$, Thomas Rosenthal ${ }^{2}$, Gordon H Guyatt ${ }^{6,7}$ and \\ Holger J Schünemann ${ }^{7}$
}

Address: ${ }^{1}$ Department of Medicine, State University of New York at Buffalo, NY, USA, ${ }^{2}$ Department of Family Medicine, State University of New York at Buffalo, NY, USA, ${ }^{3}$ Department of Internal medicine, University of Iowa, IA, USA, ${ }^{4}$ Department of Medicine, Rochester General Hospital, Rochester, NY, USA, ${ }^{5}$ Department of Medicine, University of Rochester, NY, USA, ${ }^{6}$ Department of Medicine, McMaster University, Hamilton, ON, Canada and 7 Department of Clinical Epidemiology \& Biostatistics, CLARITY Research Group, McMaster University, Hamilton, ON, Canada

Email: Elie A Akl* - elieakl@buffalo.edu; Reem Mustafa - rmustafa@buffalo.edu; Mark C Wilson - mark-c-wilson@uiowa.edu; Andrew Symons - symons@buffalo.edu; Amir Moheet - Amir.Moheet@rochestergeneral.org; Thomas Rosenthal - trosenth@buffalo.edu; Gordon H Guyatt - guyatt@mcmaster.ca; Holger J Schünemann - schuneh@mcmaster.ca

* Corresponding author

Published: 2I September 2009

Implementation Science 2009, 4:59 doi:10.1186/1748-5908-4-59
Received: 3 July 2008

Accepted: 21 September 2009

This article is available from: http://www.implementationscience.com/content/4/1/59

(C) 2009 Akl et al; licensee BioMed Central Ltd.

This is an Open Access article distributed under the terms of the Creative Commons Attribution License (http://creativecommons.org/licenses/by/2.0), which permits unrestricted use, distribution, and reproduction in any medium, provided the original work is properly cited.

\begin{abstract}
Background: Teaching the content of clinical practice guidelines (CPGs) is important to both clinical care and graduate medical education. The objective of this study was to determine the characteristics of curricula for teaching the content of CPGs in family medicine and internal medicine residency programs in the United States.
\end{abstract}

Methods: We surveyed the directors of family medicine and internal medicine residency programs in the United States. The questionnaire included questions about the characteristics of the teaching of CPGs: goals and objectives, educational activities, evaluation, aspects of CPGs that the program teaches, the methods of making texts of CPGs available to residents, and the major barriers to teaching CPGs.

Results: Of 434 programs responding (out of $839,52 \%$ ), 14\% percent reported having written goals and objectives related to teaching CPGs. The most frequently taught aspect was the content of specific CPGs (76\%). The top two educational strategies used were didactic sessions (76\%) and journal clubs (64\%). Auditing for adherence by residents was the primary evaluation strategy (44\%), although $36 \%$ of program directors conducted no evaluation. Programs made texts of CPGs available to residents most commonly in the form of paper copies (54\%) while the most important barrier was time constraints on faculty $(56 \%)$.

Conclusion: Residency programs teach different aspects of CPGs to varying degrees, and the majority uses educational strategies not supported by research evidence. 


\section{Background}

The implementation of clinical practice guidelines (CPGs) has been shown to positively impact clinical care. For example, the implementation of community-acquired pneumonia guidelines has decreased mortality [1] and improved cost effectiveness of care [2] without adverse patient consequences [3]. Diabetes care employing evidence-based guidelines [4] reduced diabetic nephropathy, retinopathy, and autonomic neuropathy. Improved survival in women with node-negative breast cancer has been associated with compliance with guidelines for systemic adjuvant treatment [5]. Use of guidelines for the management of presumed uncomplicated urinary tract infection in women has decreased laboratory utilization and overall costs while maintaining or improving the quality of care [6].

On the post graduate medical education level, teaching the content of CPGs can help in achieving three of the six general competencies defined by the Accreditation Council for Graduate Medical Education (ACGME) in the United States (US) [7]: patient care, medical knowledge, and practice-based learning and improvement [8]. It is also assumed that such teaching will help trainees to adhere to CPGs when they become independent practitioners.

In spite of their clinical and educational values, the implementation of CPGs remains suboptimal among family medicine and internal medicine trainees in the US for a number of clinical areas such as: management of hypertension [9]; management of hypercholesterolemia [10]; diagnosis and management of uncomplicated urinary tract infection [11]; screening and management of chronic kidney disease and its associated co-morbidities [12]; and screening for familial colorectal cancer [13].

One of the potential explanations for the suboptimal implementation of CPGs is suboptimal teaching of CPGs in residency programs. The main objective of this study was to determine the characteristics of curricula for teaching the content of CPGs in family medicine and internal medicine residency programs in the US. We also wanted to explore the hypothesis that a lower percentage of international medical graduates would be associated with better characteristics of teaching CPGs. It was not our objective to study either informal teaching (i.e., outside the curriculum, e.g., bedside teaching) or teaching of guidelines' development or guidelines' integration in medical decision making.

\section{Methods Study design}

We conducted a national survey of directors of family medicine and internal medicine residency programs in the US. We identified the program directors and obtained their contact information using the American Medical Association Graduate Medical Education Directory [14]. The University at Buffalo Institutional Review Board approved the study.

\section{Survey questionnaire}

To develop the questionnaire, we reviewed the medical literature including the ACGME definition of a curriculum [15] and the Cochrane Effective Practice and Organisation of Care (EPOC) review group typology of implementation interventions [16]. We also conducted discussions with five internal medicine chief residents and two program directors attending the American College of Physicians (ACP) and the Association of Program Directors in Internal Medicine (APDIM) 2005 annual meetings. Two current and one previous program director reviewed iterative versions of the questionnaire and provided feedback.

The survey questionnaire included questions about the characteristics of the teaching of CPGs: goals and objectives, educational activities, evaluation, aspects of CPGs that the program teaches, the methods of making texts of CPGs available to residents, and the major barriers to teaching CPGs. The questionnaire included additional questions about the characteristics of the program director (gender, years as program director) and the characteristics of the residency program (geographical region, affiliation, number of residents, and percentage of international medical graduates) (Additional File 1).

\section{Data collection}

We mailed program directors the initial invitation to participate in the survey in April 2007. We used the following survey methods demonstrated to maximize response rate $[17,18]$ : university sponsorship, personalized cover letter, colored ink, stamped return envelope, first class mailing, follow-up mail, including a questionnaire in the followup mail, non-monetary incentive, and a questionnaire that is interesting, short, user friendly, with factual questions, and with more relevant questions first. The nonmonetary incentive consisted of a Microsoft PowerPoint version of an educational game designed to teach CPGs and using rules similar to those of the TV show Jeopardy ${ }^{\circledast}$ [19]. We sent a follow-up mail and a follow-up fax respectively five and nine weeks after the initial invitation.

\section{Statistical analysis}

We conducted the descriptive analyses for the two specialties (family medicine and internal medicine) separately and combined. We conducted regression analyses in order to identify factors that are associated with the characteristics of the teaching of CPGs. We used logistic models with each of the options for the characteristics of the teaching of CPGs as a dependent variable, and the specialty, the 
program director characteristics, and the residency program characteristics as the independent variables (reference categories for the categorical variables were respectively: internal medicine specialty, male gender, Northeast geographical region, community based programs, and $<25 \%$ international medical graduates). We report only statistically significant associations with odds ratio $(\mathrm{OR})<0.8$ or $\mathrm{OR}<1.25$. We used Microsoft Office Access for data entry and management and SPSS, version 13.0 (SPSS, Inc., Chicago, Illinois), for all analyses.

\section{Results}

The survey overall response rate was 52\% (434 out of 839; $52 \%$ and $51 \%$ of family medicine and of internal medicine program directors responding, respectively). Table 1 lists the characteristics of the training programs combined and separately for the two specialties.

Table 2 presents the answers of responding program directors relating to questions about teaching of CPGs combined and separately for the two specialties.

Table I: The characteristics of responding program directors and of their residency programs; a national survey, 2007

\begin{tabular}{|c|c|c|c|}
\hline & Combined & Family Medicine & Internal Medicine \\
\hline & $N=434$ & $\mathbf{N}=239$ & $N=195$ \\
\hline \multicolumn{4}{|l|}{ Gender of program director, $n(\%)$} \\
\hline Female & $98(23)$ & $48(20)$ & $50(26)$ \\
\hline Years as director, mean (SD) & $7.3(5.4)$ & $6.9(5.1)$ & $7.7(5.6)$ \\
\hline \multicolumn{4}{|l|}{ Geographical region, n (\%) } \\
\hline Northeast & $129(30)$ & $47(20)$ & $82(42)$ \\
\hline South & $112(26)$ & $69(29)$ & $43(22)$ \\
\hline Midwest & $119(27)$ & $79(33)$ & $40(21)$ \\
\hline West & $68(16)$ & $40(17)$ & $28(14)$ \\
\hline \multicolumn{4}{|l|}{ Affiliation, n (\%) } \\
\hline Community based & $294(68)$ & $182(76)$ & $112(57)$ \\
\hline University based & $113(26)$ & $4 \mid(17)$ & $72(37)$ \\
\hline Military based & $15(3)$ & $8(3)$ & $7(4)$ \\
\hline Other & $6(1)$ & $4(2)$ & $2(1)$ \\
\hline Number of residents per program, mean (SD) & $36.5(28.5)$ & $22.0(8.1)$ & $53.8(34.0)$ \\
\hline \multicolumn{4}{|l|}{ International graduates, n (\%) } \\
\hline$<25 \%$ & $174(40)$ & $108(43)$ & $66(34)$ \\
\hline 25 to $50 \%$ & $85(20)$ & $53(22)$ & $32(16)$ \\
\hline 51 to $75 \%$ & $76(18)$ & $43(18)$ & $33(17)$ \\
\hline$>75 \%$ & $94(22)$ & $31(13)$ & $63(32)$ \\
\hline
\end{tabular}


Table 2: Answers to questions relating to teaching of the content of clinical practice guidelines; a national survey, 2007

\begin{tabular}{|c|c|c|c|}
\hline & Combined & Family Medicine & Internal Medicine \\
\hline & $N=434$ & $\mathbf{N}=239$ & $N=195$ \\
\hline \multicolumn{4}{|l|}{ Goals and objectives } \\
\hline Yes & $61(14)$ & $32(13)$ & $29(15)$ \\
\hline \multicolumn{4}{|l|}{ Aspects of CPGs taught } \\
\hline Identifying and locating CPGs & $310(7 I)$ & $191(80)$ & $119(61)$ \\
\hline Critical appraisal of CPGs & $222(5 \mathrm{I})$ & $130(54)$ & $92(47)$ \\
\hline Content of specific CPGs & $329(76)$ & $185(77)$ & $144(74)$ \\
\hline Dealing with conflicting CPGs & $127(29)$ & $82(34)$ & $45(23)$ \\
\hline None & $37(9)$ & $12(5)$ & $25(13)$ \\
\hline Other & $20(4.6)$ & $15(6.2)$ & $5(2.6)$ \\
\hline \multicolumn{4}{|c|}{ Educational activities to teach CPGs } \\
\hline Making texts of CPGs available & $229(53)$ & $126(53)$ & $103(53)$ \\
\hline Didactic sessions & $331(76)$ & $196(82)$ & 135 (69) \\
\hline Interactive sessions & $154(36)$ & $83(35)$ & $71(36)$ \\
\hline Journal club & $276(64)$ & $157(67)$ & $119(61)$ \\
\hline Audit and feedback to residents $*$ & $163(38)$ & $99(4 I)$ & $64(33)$ \\
\hline Self-audit by residents & $90(21)$ & $50(21)$ & $40(21)$ \\
\hline Educational games & $75(17)$ & $4 I(17)$ & $34(17)$ \\
\hline None & $23(5)$ & $5(2)$ & $18(9)$ \\
\hline Other & $25(5.8)$ & $15(6.3)$ & $10(5.1)$ \\
\hline \multicolumn{4}{|l|}{ Evaluation of the teaching of CPGs } \\
\hline Objective assessment of knowledge & $|5|(35)$ & $79(33)$ & $72(37)$ \\
\hline Assessment of attitude & $45(10)$ & $23(10)$ & $22(1 \mathrm{I})$ \\
\hline Auditing of resident adherence $*$ & $190(44)$ & $123(5 \mid)$ & $67(34)$ \\
\hline Assessment of satisfaction & $40(9)$ & $23(10)$ & $17(9)$ \\
\hline None & $157(36)$ & $78(33)$ & $79(4 I)$ \\
\hline Other & $17(3.9)$ & $9(3.7)$ & $8(4.1)$ \\
\hline
\end{tabular}


Table 2: Answers to questions relating to teaching of the content of clinical practice guidelines; a national survey, 2007 (Continued) CPGs texts made available through

\begin{tabular}{|c|c|c|c|}
\hline The website of the program & $142(33)$ & $79(33)$ & $63(32)$ \\
\hline Servers of affiliated hospital(s) & $18 \mid(42)$ & $102(43)$ & $79(4 I)$ \\
\hline email distribution & $76(18)$ & $44(18)$ & $32(16)$ \\
\hline Personal digital assistant (PDA) & $107(25)$ & $85(36)$ & $22(11)$ \\
\hline Paper copies & $236(54)$ & $136(57)$ & $100(5 \mathrm{I})$ \\
\hline None & $20(5)$ & $7(3)$ & $13(7)$ \\
\hline Other & $47(10.8)$ & $25(10.46)$ & $22(11.3)$ \\
\hline \multicolumn{4}{|l|}{ Barriers } \\
\hline Limited access to CPGs & $31(7)$ & $13(5)$ & $18(9)$ \\
\hline Insufficient interest among residents & $72(17)$ & $35(15)$ & $37(19)$ \\
\hline Insufficient interest among faculty & $96(22)$ & $41(17)$ & $55(28)$ \\
\hline Time constraints on residents & $214(49)$ & $118(49)$ & $96(49)$ \\
\hline Time constraints on faculty & $245(56)$ & 140 (59) & $105(54)$ \\
\hline \multirow[t]{2}{*}{ None } & $94(22)$ & $53(22)$ & $4 I(2 I)$ \\
\hline & $35(8.0)$ & $22(9.2)$ & $13(6.7)$ \\
\hline
\end{tabular}

*Audit can be used as an evaluation strategy but also as an educational strategy if coupled with by feedback or conducted by the residents themselves.

CPGs = Clinical Practice Guidelines

\section{Written goals and objectives}

Fourteen percent of responding program directors reported having written goals and objectives for teaching CPGs.

\section{Aspects of CPGs}

The most frequently taught aspect of CPGs was the content of specific CPGs (76\%). Nine percent of program directors reported teaching no aspect of CPGs. Teaching how to identify and locate CPGs and teaching critical appraisal of CPGs were associated with family medicine specialty (OR = 2.70; 95\% Confidence Interval (CI) 1.52 to 4.80 ) and $\mathrm{OR}=1.81 ; 95 \%$ CI 1.10 to 3.07 respectively). Teaching the content of specific CPGs was inversely associated with 51 to $75 \%$ of residents being international medical graduates $(\mathrm{OR}=0.44 ; 95 \% \mathrm{CI} 0.22$ to 0.88$)$. Teaching how to deal with conflicting CPGs was associated with female gender of the program director $(\mathrm{OR}=$ $2.00 ; 95 \%$ CI 1.17 to 3.38 ), and inversely associated with 26 to $50 \%$ of residents being international medical graduates $(\mathrm{OR}=0.45 ; 95 \%$ CI 0.23 to 0.89 ).

\section{Educational activities}

The top educational activity was didactic sessions (76\%). Five percent of program directors reported using no educational activity.

Didactic sessions were associated with family medicine specialty $(\mathrm{OR}=2.27 ; 95 \%$ CI 1.24 to 4.15$)$. Journal clubs was inversely associated with 51 to $75 \%$ of residents being international medical graduates $(\mathrm{OR}=2.05 ; 95 \% \mathrm{CI} 1.07$ to 3.92). Audit and feedback was inversely associated with 26 to $50 \%$ of residents being international medical graduates $(\mathrm{OR}=0.49 ; 95 \% \mathrm{CI} 0.27$ to 0.49$)$. Interactive sessions were associated with 26 to $50 \%$ of residents being international medical graduates $(\mathrm{OR}=1.78 ; 95 \%$ CI 1.02 to 3.08$)$.

\section{Evaluation}

The most frequently reported evaluation strategy was auditing of residents' adherence (44\%). Thirty six percent of program directors reported conducting no evaluation. 
Auditing adherence to CPGs was associated with family medicine specialty ( $\mathrm{OR}=1.72 ; 95 \% \mathrm{CI} 1.01$ to 2.94$)$ and inversely associated with 26 to $50 \%$ of residents being international medical graduates $(\mathrm{OR}=0.45 ; 95 \% \mathrm{CI} 0.26$ to 0.80$)$. Conducting objective assessment of knowledge was inversely associated with family medicine specialty $(\mathrm{OR}=0.52 ; 95 \%$ CI 0.30 to 0.90$)$.

\section{Making texts of CGPs available}

Paper copies were the most frequent format programs used to make texts of CPGs available to residents (54\%). Five percent of the program directors reported using no specific strategy to make texts of CPGs available to the residents. Making texts of CPGs available through PDAs was associated with family medicine specialty $(\mathrm{OR}=3.92$; 1.94 to 7.93 ).

\section{Barriers}

The top reported barrier was the time constraints on faculty $(56 \%)$. Twenty two percent of responding program directors reported no barriers. Considering time constraints on faculty as a barrier was associated with 26 to $50 \%$ of residents being international medical graduates $(\mathrm{OR}=2.05 ; 95 \%$ CI 1.15 to 3.66$)$.

\section{Discussion}

We conducted a survey of family medicine and internal medicine residency programs to determine how family medicine and internal medicine residency programs in the US teach the content of CPGs to their residents. Fourteen percent of program directors reported having written goals and objectives related to CPGs. The most frequently taught aspect of CPGs was the content of specific CPGs (76\%). Educational activities were predominantly didactic in nature $(76 \%)$. Auditing for adherence by residents was the primary evaluation strategy (44\%), while 36\% of program directors reported conducting no evaluation. Programs made texts of CPGs available to residents most frequently in the form of paper copies (54\%), while the most important barrier was time constraints on faculty $(56 \%)$.

This study has two main strengths. First, the survey questionnaire was rigorously designed, pretested, and is based on the EPOC review group typology of implementation strategies and ACGME definition of curriculum. Second, and to our knowledge, this is the first survey attempting to describe the teaching of the content of CPGs in both family medicine and internal medicine residency programs.

The main limitation of this study is the potential for selection bias with a response rate of $52 \%$. This response rate, however, is consistent with the mean response rate of $54 \%$ to surveys of physicians published in medical journals [18]. On the other hand, surveys of pediatricians were found to be very consistent in showing only small amounts of response bias regardless of the response rate [20]. If selection bias existed, it is likely that teaching of the content of CPGs in the programs of responding directors would be of higher quality than in those of nonresponding directors. This implies that our results could reflect an optimistic characterization of teaching of the content of CPGs in general, emphasizing the need for improvement. Another important limitation is that the study did not address important aspects of training in CPGs such as bedside teaching (i.e., in concert with the care of individual patients) and integrating guidelines in medical decision making. These are however more challenging research questions that would require different study designs and different target populations to address them. In addition, the questionnaire was not detailed enough to capture details of the educational strategies (e.g., type of auditing); however, this was intended to keep the questionnaire relatively short and increase response rate.

If teaching of the content of CPGs is considered an important part of the curriculum, programs will need to develop relevant goals and objectives. Goals and objectives offer a general focus, clarify expectations for learning and attainment, and relate them to residents' clinical and didactic activities [21]. Goals and objectives are also important for any evaluation process because outcomes are results providing evidence that goals and objectives have been accomplished [21]. We believe that such goals and objectives should cover basic skills, such as searching for and critically appraising CPGs, and more advanced skills, such as integrating CPGs in medical decision making, particularly those decisions that are sensitive to patients' values and preferences and for which guideline implementation is not equivalent to $100 \%$ adherence.

It is encouraging that the majority of programs teach the content of specific guidelines. The challenge remains however with the teaching strategy. The effectiveness of the top two strategies used by the majority of programs (i.e., didactic sessions and journal clubs) is not supported by research evidence. A systematic review assessing the effectiveness of didactic sessions concluded that they are unlikely to change professional practice [22]. A review of the literature about the use of journal clubs identified no studies assessing their impact on adherence to CPGs [23].

On the other hand, the effectiveness of two teaching strategies used by a minority of programs (i.e., interactive sessions and audit and feedback) is supported by high quality research evidence. A systematic review assessing the effectiveness of interactive workshops concluded that they can result in moderately large changes [22]. Another systematic review found that audit and feedback can be 
effective in improving professional practice [24]. The effects are small to moderate, but likely to be greater when baseline adherence to recommended practice is low and when feedback is delivered more intensively [24]. Furthermore, the improved compliance may be generalizable to recommended practices not directly targeted for audit[25]

The time constraints on faculty being the most reported barrier to teaching of the content of CPGs, potential solutions include integrated approaches to evidence-based practice and teaching [26], resident-led small-group teaching [27], online tutorials [28], and educational games [29]. The effectiveness of some of these strategies remains to be proven. While the limited availability of CPGs was found in the past to be a barrier to the use of CPGs [30], the findings of this survey shows an improvement in guidelines accessibility in both paper or electronic forms, as also suggested by a recent survey of family medicine residency directors [31].

A number of reported characteristics of the teaching of CPGs were better for family medicine than for internal medicine residency programs (e.g., identifying and locating CPGs) and vice versa (e.g., conducting objective assessment of knowledge). However, the overall results are similar for the two specialties. The challenges are thus not unique to one of the two disciplines highlighting the need for collaborative efforts. We had hypothesized that a lower percentage of international medical graduates would be associated with better characteristics of teaching CPGs; although some of the associations were statistically significant, they were not consistent enough to support our hypothesis.

\section{Conclusion}

The findings of this study have important implications for graduate medical education. Taking into account competing demands and requirements, program directors need to consider the value of teaching of the content of CPGs on the clinical care and educational levels (evidence-based medicine user model [32]). The teaching of the content of CPGs can benefit from adherence to the ACGME guidelines for curricular design. A particular attention should be given to the educational strategies used given their varying effectiveness.

The findings have also important implications for research. Time constraints on faculty being the major barriers, research should evaluate the effectiveness of innovative strategies that may consume less faculty time, such as online tutorials [28], case-based on-line learning [33], and educational games [29]. An additional challenge is to identify ways to facilitate incorporation of CPGs into decision making rather than simple conformance [8]. Future research should also investigate in other educational set- ting, the interesting association between the female gender and the higher number of years as program director with positive curricular characteristics. However, the major question to explore remains whether teaching of the content of CPGs in residency influences future practice behavior of physicians, particularly integrating CPGs in decision making in a manner that is consistent with the individual patient values and preferences.

\section{Competing interests}

The authors declare that they have no competing interests.

\section{Authors' contributions}

Authors contributions: conception and design: EAA, RM, MCW, AM, and HJS; acquisition of data: EAA, RM, AS, MCW, AM, and TR; analysis and interpretation of data: EAA, GHG, and HJS; drafting of manuscript: EAA; critical revision of the manuscript for important intellectual content: EAA, RM, AS, MCW, AM, TR, GHG, and HJS; obtaining of funding: EAA, RM, and HJS.

\section{Additional material}

\section{Additional file 1}

Survey questionnaire. Reproduces the questionnaire sent to the study participants.

Click here for file

[http://www.biomedcentral.com/content/supplementary/1748-

5908-4-59-S1.DOC]

\section{Acknowledgements}

We thank Ann Grifasi, Ethel Sharp, Denise McGuigan, and Karen Devlin for their administrative assistance. We also thank all directors of family medicine residency and internal medicine programs who contributed to this study. Research for Health in Erie County, Inc., the Graduate Medical Education of the University at Buffalo, and the Society of General Internal Medicine (through a Founders Award to EAA) funded this study. HJS is funded by a European Commission: The human factor, mobility and Marie Curie Actions. Scientist Reintegration Grant (IGR 42192). The sponsors had no role in study design; in the collection, analysis, and interpretation of data; in the writing of the manuscript; and in the decision to submit the manuscript for publication. All authors read and approved the final manuscript.

\section{References}

I. Dean NC, Silver MP, Bateman KA, James B, Hadlock CJ, Hale D: Decreased mortality after implementation of a treatment guideline for community-acquired pneumonia. The American Journal of Medicine 200I, I I 0:45 I-457.

2. Nathwani D, Rubinstein E, Barlow G, Davey P: Do Guidelines for Community Acquired Pneumonia Improve the Cost Effectiveness of Hospital Care? Clinical infectious diseases 200I, 32:728-74I.

3. Marrie TJ, Lau CY, Wheeler SL, Wong CJ, Vandervoort MK, Feagan BG, for the CSI: A Controlled Trial of a Critical Pathway for Treatment of Community-Acquired Pneumonia. JAMA 2000, 283:749-755.

4. Gaede P, Vedel P, Larsen N, Jensen GV, Parving HH, Pedersen O, Gaede P, Vedel P, Larsen N, Jensen GVH, et al.: Multifactorial intervention and cardiovascular disease in patients with type 
2 diabetes[see comment]. New England Journal of Medicine 2003, 348:383-393.

5. Hebert-Croteau N, Brisson J, Latreille J, Rivard M, Abdelaziz N, Martin G, Hebert-Croteau N, Brisson J, Latreille J, Rivard M, et al:: Compliance with consensus recommendations for systemic therapy is associated with improved survival of women with node-negative breast cancer[see comment]. Journal of Clinical Oncology 2004, 22:3685-3693.

6. Saint S, Scholes D, Fihn SD, Farrell RG, Stamm WE, Saint S, Scholes $D$, Fihn SD, Farrell RG, Stamm WE: The effectiveness of a clinical practice guideline for the management of presumed uncomplicated urinary tract infection in women. American Journal of Medicine 1999, 106:636-641.

7. Accreditation Council for Graduate Medical Education (ACGME) Outcomes Project [http://www.acgme.org/Outcome/ ]

8. Staton L, Kraemer S, Patel S, Talente G, Estrada C: Peer chart audits: A tool to meet Accreditation Council on Graduate Medical Education (ACGME) competency in practice-based learning and improvement. Implementation Science 2007, 2:24.

9. Jami P, Smith P, Moningi S, Moningi V, Martin SA, Rosencrance G, Reyes BJ: Compliance with Joint National Committee 7 guidelines in hypertension management in a teaching institution.(Clinical report). American Journal of Medical Quality 2007, 22:25 I (258):

10. Goebel LJ, Bailony F, Khattak AJ, Gress TW, Goebel LJ, Bailony F, Khattak AJ, Gress TW: Physician and patient barriers to adherence with cholesterol guidelines. West Virginia Medical Journal 2006, 102:23-26.

II. Grover ML, Bracamonte JD, Kanodia AK, Bryan MJ, Donahue SP, Warner AM, Edwards FD, Weaver AL, Grover ML, Bracamonte JD, et al.: Assessing adherence to evidence-based guidelines for the diagnosis and management of uncomplicated urinary tract infection. Mayo Clinic Proceedings 2007, 82:।8I-I85.

12. Lenz $O$, Fornoni A: Chronic kidney disease care delivered by US family medicine and internal medicine trainees: results from an online survey. BMC Medicine 2006, 4:30.

13. Barrison AF, Smith C, Oviedo J, Heeren T, Schroy PC 3rd, Barrison AF, Smith C, Oviedo J, Heeren T, Schroy PC 3rd: Colorectal cancer screening and familial risk: a survey of internal medicine residents' knowledge and practice patterns. American Journal of Gastroenterology 2003, 98:1410-1416.

14. Graduate Medical Education Directory [https://catalog.amassn.org/Catalog/product/product detail.jsp?produc tld=prod I 160010$]$

15. Glossary [http://www.acgme.org/outcome/project/glossary2.asp]

16. Cochrane Effective Practice and Organisation of Care Review Group: Data Collection Checklist [http:// www.epoc.cochrane.org/Files/Website/Reviewer\%20Resources/ Data\%20Collection\%20Checklist\%20-\%20EPOC\%20-\%202007-Feb27.doc]

17. Edwards P, Roberts I, Clarke M, DiGuiseppi C, Pratap S, Wentz R, Kwan I, Cooper R, Edwards P, Roberts I, et al:: Methods to increase response rates to postal questionnaires[see comment]. Cochrane Database of Systematic Reviews 2007:MR000008.

18. Asch DA, Jedrziewski MK, Christakis NA: Response Rates to Mail Surveys Published in Medical Journals. Journal of Clinical Epidemiology 1997, 50: I I29-I I36.

19. Akl EA, Mustafa R, Slomka T, Alawneh A, Vedavalli A, Schunemann HJ, Akl EA, Mustafa R, Slomka T, Alawneh A, et al.: An educational game for teaching clinical practice guidelines to Internal Medicine residents: development, feasibility and acceptability. BMC Medical Education 2008, 8:50.

20. Cull WL, O'Connor KG, Sharp S, Tang SF, Cull WL, O'Connor KG, Sharp S, Tang S-fS: Response rates and response bias for $\mathbf{5 0}$ surveys of pediatricians. Health Services Research 2005, 40:213-226.

21. Robertson WW: The Goals and Objectives Made Easier. ACGME Bulletin 2007:2.

22. Forsetlund L, Bjørndal A, Rashidian A, Jamtvedt G, O'Brien MA, Wolf F, Davis DA, Odgaard-Jensen J, Oxman AD: Continuing education meetings and workshops: effects on professional practice and health care outcomes. Cochrane Database of Systematic Reviews 2009, 4:CD003030.

23. Lee AG, Boldt HC, Golnik KC, Arnold AC, Oetting TA, Beaver HA, Olson RJ, Carter K: Using the Journal Club to Teach and Assess Competence in Practice-based Learning and Improvement:
A Literature Review and Recommendation for Implementation. Survey of Ophthalmology 2005, 50:542-548.

24. Jamtvedt G, Young JM, Kristoffersen DT, O'Brien MA, Oxman AD: Audit and feedback: effects on professional practice and health care outcomes. Cochrane Database of Systematic Reviews 2006:CD000259.

25. Holmboe E, Scranton R, Sumption K, Hawkins R, Holmboe E, Scranton R, Sumption K, Hawkins R: Effect of medical record audit and feedback on residents' compliance with preventive health care guidelines. Academic Medicine 1998, 73:90I-903.

26. AkI EA, Izuchukwu IS, El-Dika S, Fritsche L, Kunz R, Schunemann HJ: Integrating an evidence-based medicine rotation into an internal medicine residency program. Academic Medicine 2004, 79:897-904.

27. Garfield D, Atre-Vaidya N, Sierles F: Teaching the APA Practice Guidelines to Psychiatry Residents: A Novel Strategy. Academic Psychiatry 2002, 26:70-75.

28. Bell DS, Fonarow GC, Hays RD, Mangione CM: Self-Study from Web-Based and Printed Guideline Materials: A Randomized, Controlled Trial among Resident Physicians. Ann Intern Med 2000, 132:938-946.

29. Akl EA, Schünemann HJ: Guide-O-Game: an educational game to improve Internal Medicine residents' knowledge and adherence to clinical practice guidelines. In Evidence Based Clinical Practice newsletter McMaster University; 2008: 12.

30. Bachman $\mathrm{KH}$, Mazur $\mathrm{DJ}$ : Using practice guidelines to teach residents. Acad Med 1998, 73:1 I8-119.

3I. Nowalk MP, Zimmerman RK, Middleton DB, Sherwood RA, Ko FS, Kimmel SR, Troy JA, Nowalk MP, Zimmerman RK, Middleton DB, et al.: An evaluation of immunization education resources by family medicine residency directors. Family Medicine 2007, 39:715-719.

32. Akl EA, Maroun N, Neagoe G, Guyatt GG, Schünemann HJ: EBM user and practitioner models for graduate medical education: what do residents prefer? Medical Teacher 2006, 28:192-194.

33. Stewart M, Marshall JN, Ostbye T, Feightner JW, Brown JB, Harris S, Galajda J, Stewart M, Marshall JN, Ostbye T, et al:: Effectiveness of case-based on-line learning of evidence-based practice guidelines. Family Medicine 2005, 37:|3|-138.

\section{Publish with Bio Med Central and every scientist can read your work free of charge}

"BioMed Central will be the most significant development for disseminating the results of biomedical research in our lifetime. "

Sir Paul Nurse, Cancer Research UK

Your research papers will be:

- available free of charge to the entire biomedical community

- peer reviewed and published immediately upon acceptance

- cited in PubMed and archived on PubMed Central

- yours - you keep the copyright

Submit your manuscript here:

http://www.biomedcentral.com/info/publishing_adv.asp 